Research Paper

\title{
Migration and Differentiation of GFP-transplanted Bone Marrow-derived Cells into Experimentally Induced Periodontal Polyp in Mice
}

\author{
Saeka Matsuda ${ }^{1,2}$, Masahito Shoumura ${ }^{2}$, Naoto Osuga ${ }^{2}$, Hidetsugu Tsujigiwa ${ }^{3}$, Keisuke Nakano, ${ }^{4,5}$ \\ Norimasa Okafuji ${ }^{1}$, Takanaga Ochiai ${ }^{1,5}$, Hiromasa Hasegawa ${ }^{1,5}$ and Toshiyuki Kawakami ${ }^{1}$ \\ 1. Department of Hard Tissue Research, Matsumoto Dental University Graduate School of Oral Medicine, Shiojiri, Japan \\ 2. Department of Pediatric Dentistry, Matsumoto Dental University School of Dentistry, Shiojiri, Japan \\ 3. Department of Life Science, Faculty of Science, Okayama University of Science, Okayama, Japan \\ 4. Department of Oral Pathology, Okayama University Graduate School of Medicine, Dentistry and Pharmaceutical Sciences, Okayama, Japan \\ 5. Department of Oral Pathology, Matsumoto Dental University School of Dentistry, Shiojiri, Japan \\ $\square$ Corresponding author: kawakami@po.mdu.ac.jp
}

() Ivyspring International Publisher. Reproduction is permitted for personal, noncommercial use, provided that the article is in whole, unmodified, and properly cited. See http://ivyspring.com/terms for terms and conditions.

Received: 2016.03.28; Accepted: 2016.05.26; Published: 2016.06.29

\begin{abstract}
Perforation of floor of the dental pulp is often encountered during root canal treatment in routine clinical practice of dental caries. If perforation were large, granulation tissue would grow to form periodontal polyp. Granulation tissue consists of proliferating cells however their origin is not clear. It was shown that the cells in granulation tissue are mainly from migration of undifferentiated mesenchymal cells of the bone marrow. Hence, this study utilized GFP bone marrow transplantation mouse model. The floor of the pulp chamber in maxillary first molar was perforated using $1 / 2$ dental round bur. Morphological assessment was carried out by micro $C T$ and microscopy and GFP cell mechanism was further assessed by immunohistochemistry using double fluorescent staining with GFP-S100A4; GFP-Runx2 and GFP-CD31. Results of micro CT revealed alveolar bone resorption and widening of periodontal ligament. Histopathological examination showed proliferation of fibroblasts with some round cells and blood vessels in the granulation tissue. At 2 weeks, the outermost layer of the granulation tissue was lined by squamous cells with distinct intercellular bridges. At 4 weeks, the granulation tissue became larger than the perforation and the outermost layer was lined by relatively typical stratified squamous epithelium. Double immunofluorescent staining of GFP and Runx2 revealed that both proteins were expressed in spindle-shaped cells. Double immunofluorescent staining of GFP and CD31 revealed that both proteins were expressed in vascular endothelial cells in morphologically distinct vessels. The results suggest that fibroblasts, periodontal ligament fibroblasts and blood vessels in granulation tissue were derived from transplanted-bone marrow cells. Thus, essential growth of granulation tissue in periodontal polyp was caused by the migration of undifferentiated mesenchymal cells derived from bone marrow, which differentiated into fibroblasts and later on differentiated into other cells in response to injury.
\end{abstract}

Key words: Periodontal polyp, Periodontal ligament, Cell differentiation, Immunohistochemistry

\section{Introduction}

In routine dental clinical practice, perforation of floor of the dental pulp is a common occurrence during root canal treatment for dental caries. These problems tend to be more when treating deciduous teeth in clinical pediatric dentistry. The consequence of a large perforation is chronic inflammatory hyperplasia (1). Granulation tissue grows in the periodontal ligament from the perforated dentin causing periodontal polyp, which may also grow into the pulp cavity. Experimental histopathological 
studies have been done on periodontal polyp for a long time including histological analysis and treatment (2-5). However, the origin of the cells has not been elucidated. Consequently, using an experimental system on GFP mouse bone marrow transplantation, this study revealed that the cells were derived from mesenchymal cells of the bone marrow. Our research group has been conducting studies on migration and differentiation of cells in many sites in the oral cavity and teeth by using an experimental system of GFP bone marrow transplanted mice.

Tsujigiwa et al. (6) mentioned that transplantedbone marrow-derived cells migrated to the pulp and then differentiated into pulp tissue cells in GFP mice. Muraoka et al. (7) showed that bone marrow-derived cells migrated to the periodontal tissue and then differentiated into periodontal ligament cells like macrophages and osteoclasts. Moreover, Tomida et al. (8) described the pluripotency of bone marrowderived cells, which migrated to periodontal tissue after orthodontic mechanical stress load application. Likewise, Kaneko et al. (9) cited the differentiation of cells into cellular components of the periodontal tissue.

In this study, the method of Osuga et al. (10) was implemented and the mechanism by which cellular components of the granulation tissue to induce chronic inflammation at the furcation in GFP mouse was carried out (1). Observation with micro CT (m_CT) $(11,12)$, histopathology and immunohistochemistry were followed through over specific periods of time. Double fluorescence-immunohistochemistry (FIHC) was also done and revealed remarkable results.

\section{Materials and Methods}

\section{Preparation of GFP bone marrow-transplanted mice}

Eleven, 7 week-old male C57BL/6 mice weighing $25 \pm 2 \mathrm{~g}$ received bone marrow transplantation referring to GFP transgenic mouse (GFP mouse) (Table 1), (13, 14). To harvest bone marrow derived-GFP cells, GFP transgenic mice were sacrificed using ether anesthesia and the femur was taken. The surrounding soft tissues on the femur were removed as much as possible and the bone marrow cells were harvested. Harvested bone marrow cells were washed in RPMI 1640 medium containing antibiotics, substituted with HBBS and then subjected to $x$-ray irradiation of 10 Gray. Then after, $1 \times 10^{7}$ bone marrow cells were implanted into the tail vein of 7 -week old syngeneic mice $(15,16)$. The experiment commenced five weeks after bone marrow transplantation.
Table 1. Number of Experimental Animals

\begin{tabular}{llllll}
\hline Periods & 2 weeks & 1 month & 3 months & 6 months & Total \\
\hline Number & 2 & 2 & 3 & 4 & 11 \\
\hline
\end{tabular}

\section{Perforation of the floor of pulp chamber}

Pentobarbital sodium (Somnopentyl, Kyoritsu Seiyaku Corp, Tokyo, Japan) was injected into the abdominal cavity of mouse for general anesthesia. The mouse was fixed on the plate and hole was drilled on the crown of maxillary left first molar using $1 / 2$ round bur (Maillefer Ballaigues Suisse) to create a perforation of floor of the dental pulp. The animals were sacrificed at 2 weeks, 1 month, 3 months and 6 months. The tissues were then removed and photographed using $\mathrm{m} \_\mathrm{CT}$. The present study was approved by the Animal Experiment Committee of Matsumoto Dental University and Okayama University Graduate School of Medicine, Dentistry and Pharmaceutical Sciences.

\section{Histological preparation}

After each experimental period, the mass was excised, fixed in $4 \%$ neutral buffered formalin solution and then demineralized in $10 \%$ EDTA solution. After washing, tissues were dehydrated in increasing series of alcohol, embedded in paraffin and sectioned serially into $4 \mu \mathrm{m}$. Then after, sections were deparaffinized and stained with H-E and TRAP/ALP stain (Wako Pure Chemical Industries, Ltd., Osaka, Japan).

\section{Immunohistochemistry}

Immunohistochemistry (IHC) was done using GFP and Runx2 proteins. Briefly, deparaffinized sections were immersed in xylene, pre-treated in protease solution (Histofine protease, Nichirei Biosciences, Tokyo, Japan) for $5 \mathrm{~min}$ at room temperature and then subjected to heat treatment using autoclave at $121{ }^{\circ} \mathrm{C}$ for $10 \mathrm{~min}$. This was followed by endogenous peroxidase blocking reagent (peroxidase blocking, Dako Japan Co, Ltd, Tokyo, Japan) for $10 \mathrm{~min}$ at room temperature and by non-specific blocking reagent (Protein Blocking, serum-free, Dako Japan Co, Ltd, Tokyo, Japan) for 20 min at room temperature. Hereinafter, primary antibodies were used at $4{ }^{\circ} \mathrm{C}$ for 16 hours (Table 2). Peroxidase-labeled polymer of primary antibody (Simple Stain Mouse MAX-PO ${ }^{\circledR}$, Nichirei Biosciences, Tokyo, Japan) was allowed to react for 30 min at room temperature and was developed using DAB (Liquid DAB + Substrate Chromogen System, Dako Japan Co, Ltd, Tokyo, Japan). Table 2 shows the primary antibodies used. 
Table 2. Antibody used

\begin{tabular}{|c|c|c|c|c|}
\hline & Antibody & Source & IHC & FIHC \\
\hline Anti-GFP & ab290 & $\begin{array}{l}\text { Abcam, } \\
\text { Cambridge }\end{array}$ & - & $1: 300$ \\
\hline Anti-S100A4 & ab197896 & $\begin{array}{l}\text { Abcam } \\
\text { Cambridge }\end{array}$ & $1 / 2000$ & $1 / 30-1 / 100$ \\
\hline Anti-Runx2 & sc-10758 & $\begin{array}{l}\text { Santa Cruz } \\
\text { Biotech }\end{array}$ & - & $1 / 150$ \\
\hline Anti-CD31 & ab28364 & $\begin{array}{l}\text { Abcam, } \\
\text { Cambridge }\end{array}$ & $1 / 100$ & $1 / 150$ \\
\hline
\end{tabular}

\section{Immunofluorescence double staining}

After deparaffinization, slides were pre-treated in citrate buffer in microwave for 1 min followed by blocking with $10 \%$ donkey normal serum for $30 \mathrm{~min}$ at room temperature. The primary antibodies used namely anti-GFP, anti-S100A4, anti-Runx2, anti-CD31, Can Get Signal (Toyobo Co, Ltd, Osaka, Japan at 100-fold) and were allowed to react overnight at $4{ }^{\circ} \mathrm{C}$.

Secondary antibodies used were Alexa Fluor 568 Labeled Donkey Anti-Goat IgG Antibodies (Life Technologies, Palo, Alto, CA, USA), Alexa Fluor 488 Labeled Donkey Anti-Rat IgG Antibodies (Life Technologies, Palo, Alto, CA, USA) and Can Get Signal (Toyobo Co, Ltd, Osaka, Japan), diluted at 200-fold and reacted for $60 \mathrm{~min}$ at room temperature. DAPI $1 \mathrm{mg} / 3 \mathrm{ml}$ for $3 \mathrm{~min}$ was used for nuclear counterstain. After washing with TBS, slides were mounted using Fluorescent Mounting Medium (Dako Japan, Co, Ltd, Tokyo, Japan).

\section{Results}

\section{Observation with $\mathbf{m} \_\mathbf{C T}$}

At 2 weeks, there was a slight resorption of alveolar bone and expansion of the width of periodontal ligament underneath the perforation (Fig. 1-a). At 1 month, the expansion of the width of periodontal ligament became wider (Fig. 2-a) and at 3 months, resorption of the alveolar bone was more apparent and the crown of the tooth has completely collapsed (Fig. 3-a). At 6 months, widening of the periodontal ligament from furcation to the apex of the root was evident (Fig. 4-a).

\section{Histopathological observation}

At 2 weeks, slight neutrophil infiltration immediately below the perforation was spotted in which a portion was in contact with the dentin wall. The proliferating cells were similar in morphology to the fibroblasts, which are short and spindle in shape with relatively round nucleus. There was an irregularity in the arrangement. Capillaries were present to a certain degree in some places in the granulation tissue. Polygonal epithelial cells with distinct intercellular bridges covered the outermost layer of the granulation tissue. Multinucleated giant cells were observed in some Howship's lacuna (Fig. $1-b, c)$. The cells showed positive red staining with TRAP.

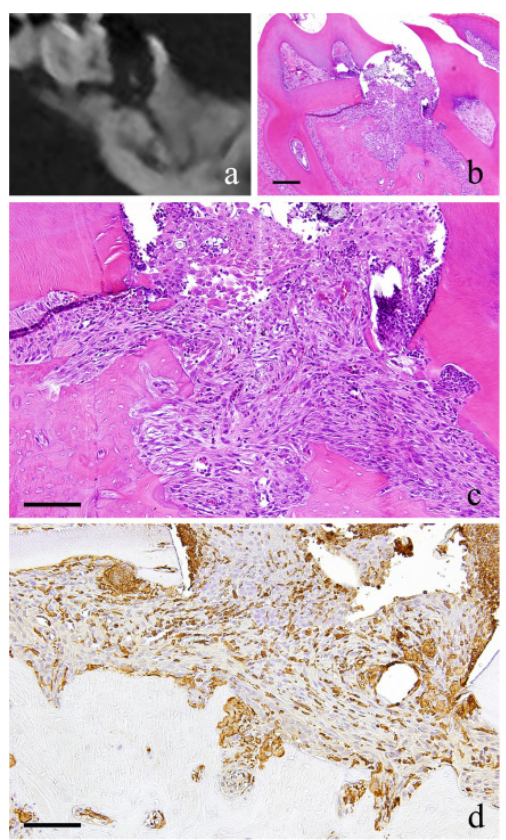

Figure 1. 2-week-specimen. a: m_CT image; b: Histopathological view of the same part of a, Scale bar $=200 \mu \mathrm{m}$; c: Enlarged view of b, Scale bar $=100 \mu \mathrm{m}$; d: IHC for GFP, Scale bar $=100 \mu \mathrm{m}$.

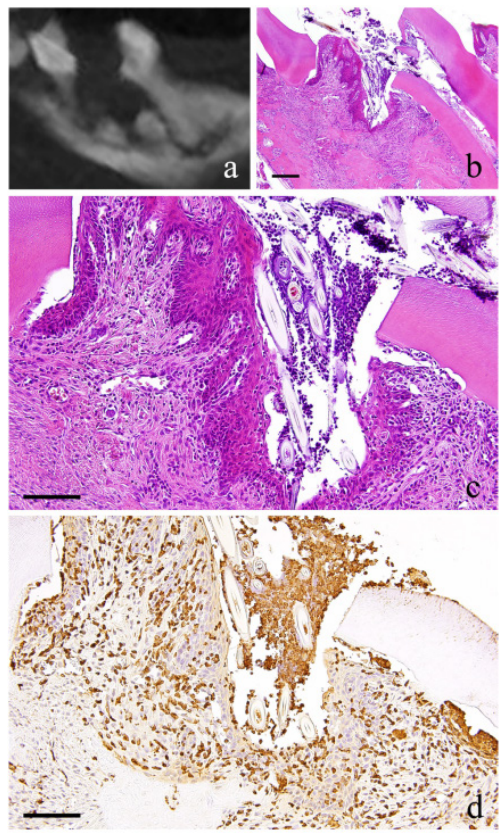

Figure 2. 1-month-specimen. a: $m_{-}$CT image; b: Histopathological view of the same part of a, Scale bar $=200 \mu \mathrm{m}$; c: Enlarged view of b, Scale bar $=100 \mu \mathrm{m}$; d: IHC for GFP, Scale bar $=100 \mu \mathrm{m}$. 


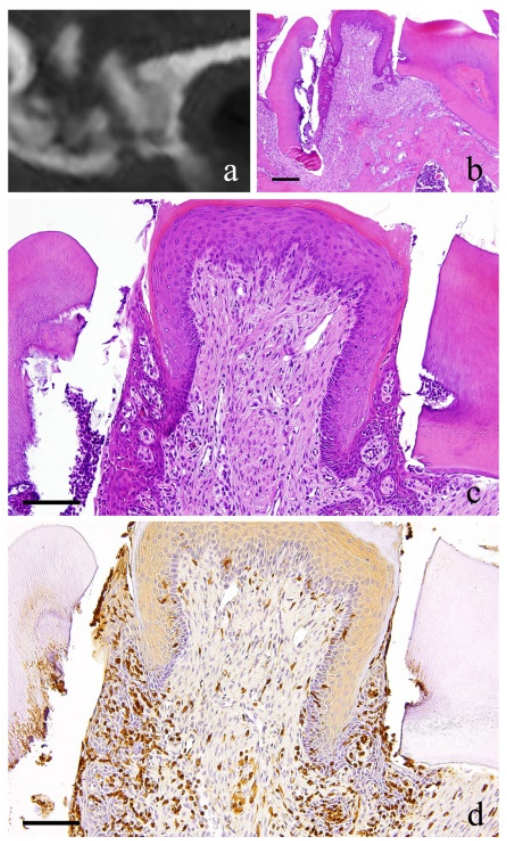

Figure 3. 3-month-specimen. a: $m$ CT image; b: Histopathological view of the same part of a, Scale bar $=200 \mu \mathrm{m}$; c: Enlarged view of b, Scale bar $=100 \mu \mathrm{m}$; d: IHC for GFP, Scale bar $=100 \mu \mathrm{m}$.

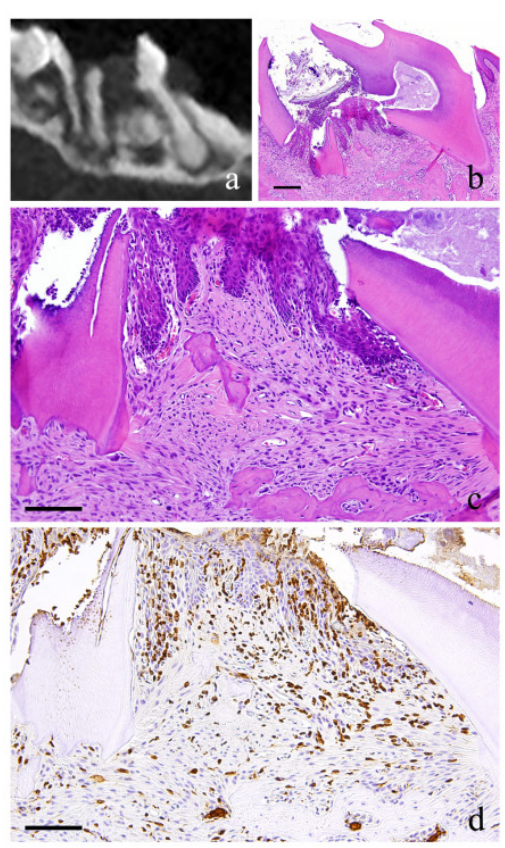

Figure 4. 6-month-specimen. a: $m \_C T$ image; b: Histopathological view of the same part of a, Scale bar $=200 \mu \mathrm{m}$; c: Enlarged view of b, Scale bar $=100 \mu \mathrm{m}$; d: IHC for GFP, Scale bar $=100 \mu \mathrm{m}$

At 1 month, the fibroblasts with round nucleus seen at 2 weeks were also spotted but not in the main part of the granulation tissue. The granulation tissue directly underneath the perforation became bigger and grew inside the pulp chamber; the outermost layer is covered with stratified squamous epithelium. The basal layer of the epithelium showed some sort of activity. Proliferation of capillaries increased compared to 2 weeks and most of them were found just beneath the epithelium (Fig. 2-b, c).

At 3 months, the nucleus of fibroblasts in the granulation tissue became flat. Proliferation of collagen fibers was also evident. Likewise, the stratified squamous epithelial lining became thicker. Capillaries in the granulation tissue also increased at its peak (Fig. 3-b, c).

At 6 months, there were continuous growth in the granulation tissue, increased collagen fibers, more fibroblasts with more conspicuous flat nucleus and scattered lymphocytes. However, capillaries have slightly decreased (Fig. 4-b, c).

\section{Protein expressions}

At 2 weeks, long and spindle in shape cells with spindle shape nucleus as well as vascular endothelial cells were positive to GFP. In addition, multinucleated giant cells in the area of alveolar bone resorption were also positive to GFP (Fig. 1-d).

At 1 month, many GFP-positive cells were present in the periodontal polyp underneath the perforation (Fig. 2-d). At 3 months, the spindle-shaped cells and polygonal cells were also positive to GFP. Furthermore, the epithelial layer was negative to GFP and the cells exhibited regular morphology (Fig. 3-d). However, some GFP-positive cells, having irregular cytoplasm in shape, were observed. GFP-positive reaction was continuously detected at 6 months (Fig. 4-d). GFP-positive cells were detected as early as 2 weeks and then an increase in expression was noted at 1 month. Nevertheless, no further increase was observed thereafter.

The cells inside the capillary were not clear but their expression of CD31 made them discernible. The most number of capillaries was observed at 3 months.

Immunofluorescence double staining of GFP and S100A4 from 2 weeks to 6 months showed GFP-positive cells with green fluorescence in long spindle-shaped cells with spindle-shape nucleus (Fig. 5 -a) and S100A4 was also detected in cell outline in red fluorescence (Fig. 5-b). Superimposition of both proteins was confirmed in areas where orange stain was found (Fig. 5-c). Superimposition in the nucleus was also captured by the orange color with blue fluorescence at periphery of the nucleus (Fig. 5d).

Immunofluorescence double staining of GFP and Runx 2 showed both spindle cells with round nucleus and elongated cells in the granulation tissue were positive to GFP emitting green fluorescence (Fig. 6-a) and Runx2 was also detected in the outline of the cells in red fluorescence (Fig. 6-b). During superimposition, a match between the two proteins was observed indicated by the orange stain (Fig. 6-c). Further superimposition with DAPI showing blue 
fluorescence in the nucleus showed orange stain at the periphery of the nucleus (Fig. 6-d).

Runx2-positive and GFP-positive cells that developed an orange stain indicated superimposition of the two proteins. A significant increase in superimposition was observed from 2 weeks to 1 month then decreased at 3 months. The superimposition at 6 months indicated the reaction of both Runx2-positive cells and GFP-positive cells. However, there were many cells only stained individually by GFP.
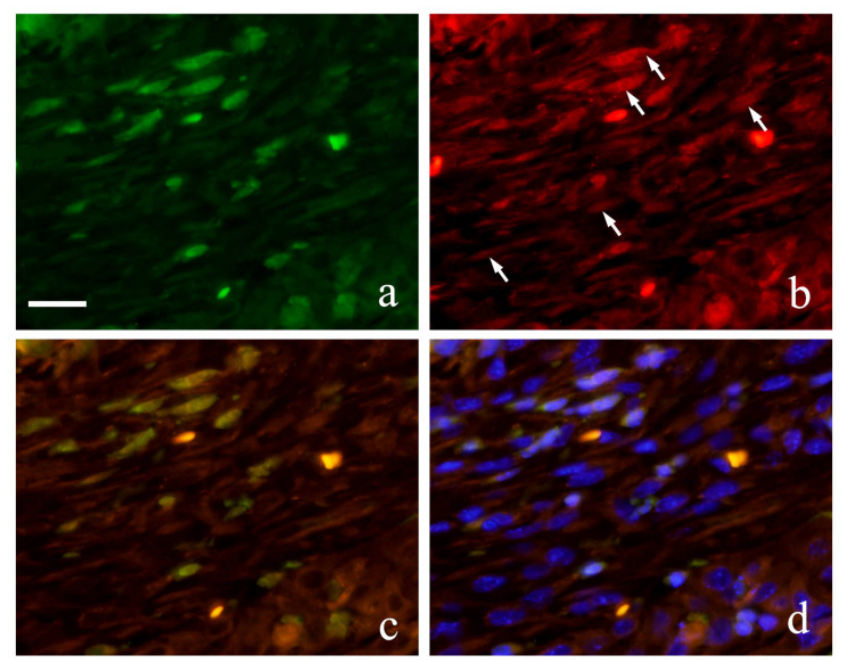

Figure 5. FIHC images of periodontal polyp (a: GFP; b: S100A4; c: merged image of GFP and S100A4; and d: merged image of S100A4, GFP and DAPI; 2 week specimen; scale bar $=20 \mu \mathrm{m}$ ).
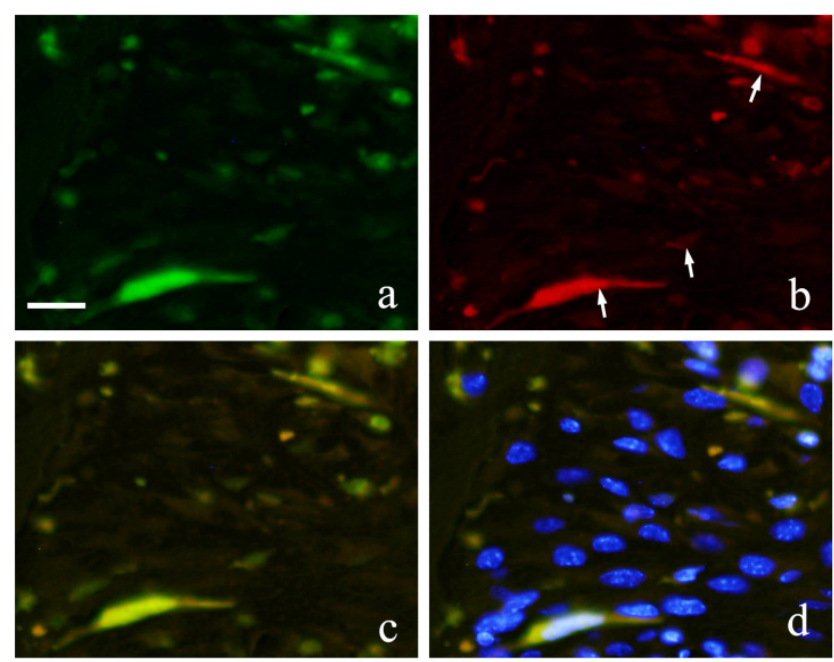

Figure 6. FIHC images of periodontal polyp (a: GFP; b: Runx2; c: merged image of GFP and Runx2; and d: merged image of Runx2, GFP and DAPI; 2 week specimen; scale bar $=20 \mu \mathrm{m}$ ).

Both GFP and CD31 were clearly expressed by cells in the blood vessels. GFP expression in the cytoplasm of vascular endothelial cells was marked by green fluorescence (Fig. 7-a) and CD31 positive reaction was marked by red fluorescence (Fig. 7-b).
Superimposition of the two proteins was least at 2 weeks (Fig. 7-c). At 1 month, an increase in both CD31 and GFP-positive cells was observed.
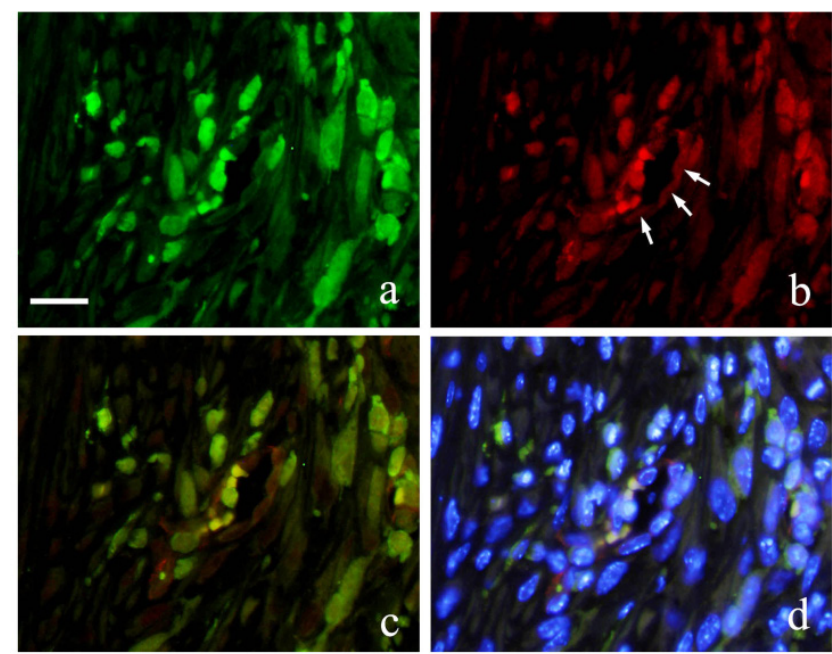

Figure 7. FIHC images of periodontal polyP (a: GFP; b: CD31; c: merged image of GFP and CD31; and d: merged image of CD31, GFP and DAPI; 2 week specimen; scale bar $=20 \mu \mathrm{m})$.

\section{Discussion}

Accidental perforation of floor of the dental pulp is contingent during endodontic treatment. Various conventional dental materials have been used to seal the perforation but not all prognoses were certainly good. Oka et al. (2) used rat to observe the response of periodontal tissue at the furcation associated with medullary pulpal perforation. In a similar study, Imaizumi et al. (3) discussed the enlargement of inflammatory lesion at the furcation. Other animal studies presented the formation of inflammatory lesion as a consequence of perforation of the floor of the pulp chamber. Kudo et al. (4) and Ishida et al. (5) as well as other numerous researches showed the histopathological analysis and treatment following perforation at the furcation area. A detailed histopathological examination by Nakamura et al. (17) showed the continuous growth of granulation tissue in the periodontal ligament. Moreover, to separate and distinguish the periodontal polyp from the growth of the pulp tissue is difficult. Although previous studies have been made, the focus was just on histopathological examination and the origin of the cellular components of the granulation tissue at the furcation was not mentioned.

Recently, the role of undifferentiated mesenchymal cells derived from bone marrow has been widely studied to play a role in periodontal tissue, bone and in other organs. By using bone defect, cementoblast and fibroblast-like cells were produced 
in the periodontal ligament and alveolar bone by undifferentiated mesenchymal cells from the bone marrow (18-20). Since GFP transgenic mice expressed the protein, all cells that constitute the tissue and even those that differentiated into any cell from transplanted bone marrow-derived cells can be traced because they carry the protein $(13,14)$. Thus, the study used an experimental system using GFP mice and induced perforation of floor of the dental pulp of maxillary left first molar. With the development of the lesion at the furcation, the origin of the cellular component responsible for the growth of the periodontal polyp was clarified.

Results showed that at 2 weeks, inflammatory cells such as neutrophils were present in response to the physiological mechanism of the periodontal tissue. This was followed by the increase in the fiber component of the granulation tissue as the number of inflammatory cells decreased. Experimental perforation of floor of the dental pulp in mice caused a slight initial suppurative inflammation leading to granulation tissue growth due to gradual chronic inflammation. Similar results were observed from previous experiment (1).

Cells having spindle-shaped nucleus, blood vessels and multinucleated giant cells in areas of bone resorption immediately below the perforation were positive to GFP. Moreover, GFP-positive cells were also spotted to have infiltrated the epithelium, although there were no positive cells in the epithelium. Therefore, the cells are considered to be dendritic cells. Thus, it would also be reasonable to consider that the cells were derived from mesenchymal cells of the bone marrow. In order to identify the GFP-positive cells, double FIHC staining for each marker was performed.

Muraoka et al. (7) and Kaneko et al. (9) strongly suggested that fibroblasts originated from the migration and differentiation of bone marrow cells to the periodontal ligament when experimentally induced. In order to identify the fibroblasts, S100A4 and Runx2 were used since there is no perfect marker for fibroblasts (21-23). The expression of S100A4 in periodontal ligament was reported to be blocking the calcification in periodontal ligament (24). However, Saito et al. (25) and Watanabe et al. (26) mentioned that periodontal ligament fibroblast is different from the ordinary fibroblast in homeostasis where in Runx2 is weakly expressed.

Many spindle cells with spindle nucleus were positive to S100A4. These cells were also positive to GFP, which means that these cells were undifferentiated mesenchymal cells that migrated and differentiated into fibroblasts. Runx 2 was examined and a number of spindle shaped cells with spindle shaped nuclei were both positive to GFP and Runx2. Thus, these cells were derived from transplanted-bone marrow cells, which later on differentiated into local periodontal ligament fibroblasts. Moreover, the fibroblast-like cells that were positive to both S100A4 and Runx 2 were derived from the bone marrow.

Sakai et al. (27) observed the reaction of granulation tissue from foreign substances in the body and a portion of the fibroblasts and capillary endothelial cells were revealed to be bone marrow-derived mesenchymal cells. Immunostaining with CD31, a marker of endothelial cells showed positive reaction in vascular endothelial cells, which also showed positive reaction to GFP. Therefore, some of the capillaries were obtained from the migration and differentiation of undifferentiated mesenchymal cells from the bone marrow cells. Similar observation was also mentioned by Sakai et al. (27) in which chronic inflammation and angiogenesis progressed constantly not only due to the local endothelial cell proliferation but also probably due to the continuous the migration of mesenchymal cells from the bone marrow.

From the above results and overall consideration, fibroblasts, periodontal ligament fibroblasts and blood vessels are essential in the growth of periodontal polyp due to perforation on the floor of the pulp chamber. Furthermore, the osteoclasts observed on the surface of the alveolar bone beneath the perforation originated from transplanted bone marrow cells.

\section{Acknowledgments}

This study was supported in part by Grant-in-Aid for Scientific Research (C) \#25463204, (C) \#26463104, (C) and \#26463031 from the Japan Society for the Promotion of Science.

\section{Competing Interests}

The authors have declared that no competing interest exists.

\section{References}

1. Matsuda S, Yokoi Y, Moriyama K, Shoumura M, Osuga N, Nakano K and Kawakami T. Pathological examination of experimentally induced periodontal polyp in mice. J Hard Tissue Biol. 2015; 24: 397-400.

2. Oka Y, Yoshikawa M, Takemura M, Yamamoto K and Toda T. Histological examination on periodontal tissue reaction of rat molar following perforation of the chamber floor. Jpn J Conserv Dent. 1991; 34: 1574-1579.

3. Imaizumi I, Iwama A, Shibata N, Kumazawa M, Yamasaki M, Nakamura H and Kameyama Y. Experimental studies on lesion progression following perforation of the furcation area of rat molars. Aichi Gakuin J Dent Sci. 1996; 34: 717-723.

4. Kudoh J. A study on the treatment of the furcation perforation using germfree rat. Jpn J Conserv Dent. 1989; 32: 201-213.

5. Ishida T, Tachibana T, Sato K, Sawada M, Watanabe K, Endo M, Saito H, Takeda $\mathrm{Y}$ and Ishibashi M. Experimental study of endodontic treatment for furcation perforation. Jpn J Concerv Dent. 1985; 28: 1372-1382.

6. Tsujigiwa H, Katase N, Sathi GA, Buery RR, Hirata Y, Kubota M, Nakano K, Kawakami $\mathrm{T}$ and Nagatsuka $\mathrm{H}$. Transplanted bone marrow derived cells 
differentiated to tooth, bone and connective tissues in mice. J Hard Tissue Biol. 2011; 20: 147-152.

7. Muraoka R, Tsujigiwa H, Nakano K, Katase N, Tamamura R, Tomida M, Okafuji N, Nagatsuka $\mathrm{H}$ and Kawakami T. Transplanted bone marrow-derived cell migration into periodontal tissues and cell differentiation. J Hard Tissue Biol. 2011; 20: 301-306.

8. Tomida M, Tsujigiwa H, Nakano K, Muraoka R, Nakamura T, Okafuji N, Nagatsuka $\mathrm{H}$ and Kawakami T. Promotion of transplanted bone marrow-derived cell migration into the periodontal tissues due to orthodontic mechanical stress. Int J Med Sci. 2013; 10: 1321-1326.

9. Kaneko K, Matsuda S, Muraoka R, Nakano K, Iwasaki T, Tomida M, Tsujigiwa $\mathrm{H}$, Nagatsuka $\mathrm{H}$ and Kawakami T. Histological evaluation of periodontal ligament in response to orthodontic mechanical stress in mice. Int J Med Sci. 2015; 12: 689-694.

10. Osuga N, Matsuda S, Shoumura M, Moriyama K, Nakano K and Kawakami T. Establishment of experimental periapical inflammatory lesions in mice. J Hard Tissue Biol. 2013; 22: 517-520.

11. Min S, Sato S, Saito M, Ebihara H, Arai Y and Ito K. Micro-computerized tomography analysis: dynamics of bone augmentation within a titanium cap in rabbit calvarium. Oral Surg Oral Med Oral Pathol Oral Radiol Endod. 2008; 106: 892-895.

12. Arai $Y$, Yamada A, Ninomiya T, Kato T and Masuda $Y$. Micro-computed tomography newly developed for in vivo small animal imaging. Oral Radiol. 2005; 21: 14-18.

13. Okabe M, Ikawa M, Kominami K, Nakanishi T and Nishimune $Y$. 'Green mice' as a source of ubiquitous green cells. FEBS Lett. 1997; 407: 313-319.

14. Ikawa M, Yamada S, Nakanishi T and Okabe M. Green flourecsent protein (GFP) as a vital maker in mammals. Curr Top Dev Biol. 1999; 44: 1-20.

15. Wall DA, Hamberg SD, Reynolds DS, Burakoff SJ, Abbas AK and Ferrara JL. Immunodeficiency in graft-versus-host disease. I. Mechanism of immune suppression. J Immunol. 1998; 140: 2970-2976.

16. Zijlmans JM, Visser JW, Leterveer L, Kleiverda K, Heemskerk DP, Kluin PM, Willemze R and Fibbe WE. The early phase of engraftment after murine blood cell transplantation is mediated by hematopoietic stem cells. Proc Natl Acad Sci USA. 1998; 95: 725-729.

17. Nakamura C, Hayashi T, Iso K and Nakamura F. A case of periondontal polyp, clinically resembled to pulp polyp. Matsumoto Shigaku (J Matsumoto Dent Univ Sci). 1979; 5: 89-93

18. Kramer PR, Kramer SF, Puri J, Grogan D and Guan G. Multipotent adult progenitor cells acquire periodontal ligament characteristics in vivo. Stem Cells Dev. 2009; 18: 67-75.

19. Yamazaki K. Periodontitis and tissue regeneration. Nihon Hotetsu Shika Gakkai Zasshi. 2005; 49: 587-592.

20. Nakajima R, Ono M, Hara ES, Oida Y, Shinkawa S, Pham HT, Akiyama K, Sonoyama W, Maekawa K and Kuboki T. Mesenchymal stem/progenitor cell isolation from tooth extraction sockets. J Dent Res. 2014; 93: 1133-1140.

21. Zhang J, Chen L, Liu X, Kammertoens $\mathrm{T}$, Blankenstein $\mathrm{T}$ and Qin Z. Fibroblast-specific protein 1/S100A4-positive cells prevent carcinoma through collagen production and encapsulation of carcinogens. Cancer Res. 2013; 73: 2770-2781.

22. Zeisberg EM, Potenta SE, Sugimoto H, Zeisberg M and Kalluri R. Fibroblasts in kidney fibrosis emerge via endothelial to-mesenchymal transition. J Am Soc Nephrol. 2008; 19: 2282-2287.

23. Kong P, Christia P, Saxena A, Su Y and Frangogiannis NG. Lack of specificity of fibroblast-specific protein 1 in cardiac remodeling and fibrosis. Am J Physiol Heart Circ Physiol. 2013; 305: 1363-1372.

24. Duarte WR, Iimura T, Takenaga K, Ohya K, Ishikawa I, Kasugai S. Extracellular role of S100A4 calcium-binding protein in the periodontal ligament. Biochem Biophys Res Commun. 1999; 255: 416-420.

25. Saito Y, Yoshizawa T, Takizawa F, Ikegame M, Ishibashi O, Okuda K, Hara K, Ishibashi $\mathrm{K}$, Obinata $\mathrm{M}$ and Kawashima $\mathrm{H}$. A cell line with characteristics of the periodontal ligament fibroblasts is negatively regulated for mineralization and Runx2/Cbfa1/Osf2 activity, part of which can be overcome by bone morphogenetic protein-2. J Cell Sci. 2002; 115: 4191-4200.

26. Watanabe T, Nakano K, Shimizu T, Okafuji N, Kurihara S, Yamada K and Kawakami T. Immunohistochemistry of the periodontal ligament fibroblasts in orthodontic tension sides. J Hard Tissue Biol. 2009; 18: 175-180.

27. Sakai K, Nakano K, Matsuda S, Tsujigiwa H, Ochiai T, Shoumura M, Osuga N, Hasegawa $\mathrm{H}$ and Kawakami T. Pathological analysis of cell differentiation in Cholesterol Granulomas experimentally induced in mice. Int J Med Sci. 2016; 13: 220-224. 